\title{
Incorporating health into environmental assessments in Canada
}

\author{
Emily Peterson* and Tom Kosatsky* \\ *National Collaborating Centre for Environmental Health, BC Centre for Disease Control, Vancouver, BC, Canada.
}

Environmental assessment (EA) is a process used to assess the environmental effects of proposed initiatives such as industrial, transportation, water management, and development projects. EAs are conducted federally in all provinces and territories in Canada and are used to inform mitigation and project approval. Although the process varies across the country, all EAs emphasize consideration of the environmental effects of a project with varying degrees of regard paid to potential economic, social, and health impacts (Bond, 2004; Health Canada, 2004a). Overall, health has not been consistently incorporated into environmental assessments; as a consequence, there may be missed opportunities for the mitigation of negative health impacts and the enhancement of positive health impacts. Environmental public health practitioners can play an important role in providing a health perspective to EA.

\section{Why should health be incorporated into $E A$ ?}

Projects that undergo EAs, such as resource extraction and development projects, can lead to changes in our physical (e.g., air quality, access to green space), social (e.g., personal connectedness, traditional practices), and economic (e.g., job creation/loss) environments that can impact human health (World Health Organization, 2015). To address the impacts of changes to these environments on health, assessors need to capture ways in which these projects can change the physical and social milieu and anticipate ways in which those changes might impact health.

The incorporation of health into EAs could reduce the negative health impacts of a project undergoing EA and its associated economic costs in addition to promoting the positive health impacts (Davies and Sadler, 1997; Health Canada, 2004a; Kwiatkowski, 2004). This can be illustrated using an example involving a proposed new development in San Francisco that would have displaced many low income residents. The city's local public health department advocated for a change in the scope of

Corresponding author: Emily Peterson (e-mail: emily.peterson@ bccdc.ca) the EA to include residential displacement and the associated indirect impacts on health such as psychological stress, food insecurity due to increased rent burden, and loss of supportive social networks. This request led to the inclusion of fixed-rent units in the development for the individuals who would have been displaced (Bhatia, 2007).

The inclusion of health into EAs can also ensure that decision makers have access to information on the health, environmental, and economic impacts of a project through one process and at one point in time to better inform project approval (Davies and Sadler, 1997; Health Canada, 2004a; Kwiatkowski, 2004).

\section{Health is insufficiently incorporated into EA}

Reports in Canada and worldwide have indicated that health is inconsistently incorporated into EA largely as a consequence of the restriction of health concerns to a small number of direct physical health effects, with limited attention given to indirect effects and social impacts on health (Davies and Sadler, 1997; Bond, 2004; Kwiatkowski, 2004; Noble and Bronson, 2005, Noble and Bronson, 2006; McCaig, 2006; Bhatia and Wernham, 2008). This is illustrated in a compilation of case studies looking at the inclusion of health in EAs for proposed mining developments in northern Canada (Noble and Bronson, 2005). In an EA for the decommissioning of a uranium mine, the primary health focus was on direct and indirect exposures to radiation through contaminated water, whereas other potential indirect health impacts and social factors were not addressed such as the potential for the project to disrupt traditional hunting and land-use patterns (Noble and Bronson, 2005). Other EAs reviewed included a broader range of health considerations but were still criticized for insufficient attention to social conditions, such as substance abuse and community violence, in addition to inadequate monitoring and follow-up (Noble and Bronson, 2005). The authors of these case studies conclude that health determinants are inconsistently incorporated into EA, and when they are 
included, it is often done poorly and with little follow-up monitoring (Noble and Bronson, 2005).

A survey of government EA practitioners, EA consultants, and federal and regional health practitioners in northern Canada identified a number of barriers limiting the integration of health into EAs (Noble and Bronson, 2006). These included: differences in practitioners' understanding of how well health is integrated into EA, with some EA practitioners and proponents rating it as sufficient, whereas First Nations participants and some health practitioners suggest it is insufficient; limited coordination and communication between health practitioners and those who work in EA; lack of supporting EA methods and frameworks to deal with the complexity of health impacts from environmental effects; limited access to health data; and a lack of financial and time resources (Noble and Bronson, 2006).

\section{How can health be incorporated into EA?}

The incorporation of health into EA remains a challenge; however, there are some examples in Canada where EA has begun to include a wider scope of health and address the interactions between the social and physical environments and human health and well-being (Kwiatkowski and Ooi, 2003; Orenstein et al., 2010). One such example is a federal integrated environmental impact assessment of a diamond mining project in a northern Canadian community. The EA was performed using a Public Review Panel that consisted of members who had expertise in law, aboriginal issues, geological services, and economic policy (Kwiatkowski and Ooi, 2003). This panel was responsible for reviewing the EA report, receiving input from public hearings, and preparing recommendations. The recommendations comprised a broad range of considerations relevant to health including Aboriginal rights, traditional knowledge, monitoring of environmental and socioeconomic programs, environmental management, site security, air quality, water quality, wildlife, employment, and compensation (Kwiatkowski and Ooi, 2003). Another example in Alberta used a multidisciplinary team of consultants with expertise in the environment, social, and health disciplines as well as two community-based coordinators to examine the potential impacts of a heavy oil pilot project (Orenstein et al., 2010). The consultants worked together to develop the initial conceptual models of potential impacts and collaborated with the community coordinators through the entire assessment. These examples demonstrated the need for a multi-stakeholder approach and the importance of community involvement when addressing the complex environmental, social, and health impacts of a project undergoing EA.

Considerations that need to be addressed to effectively incorporate health into EA include:

- increased awareness about the benefits of including health into EA among EA reviewers and consultants, health professionals, decision makers, and the public (Health Canada, 2004a);

- stronger collaboration between agencies responsible for EA and public health authorities (Health Canada, 2004a; Kwiatkowski, 2004; Bhatia and Wernham, 2008);

- more and better-qualified staff to allow public health agencies the time to engage in EAs and gain the knowledge required to examine the potential health effects of a project (Bhatia and Wernham, 2008);

- engagement between public health and the public to familiarize health agencies with community concerns surrounding EAs, to address these concerns (Bhatia and Wernham, 2008);

- improved follow-up and monitoring of population health parameters after an EA has been completed to increase knowledge and documentation of the project impacts on health (Health Canada, 2004a);

- development of analytical methods and tools that will help predict the health impacts of future projects (Bhatia and Wernham, 2008).

Public health practitioners have the education and experience to understand the mechanisms of health and disease. This understanding can help to connect the various economic, social, and environmental impacts of a proposed project to the complex array of potential health impacts. A number of approaches to EA involvement are possible, including and not limited to participating in working groups and providing feedback on submissions during the comment periods. No one public health practitioner will have the expertise to assess all of the potential health impacts of a project but they can bring organizations and other experts together during an EA to ensure that these impacts are adequately addressed. Health Canada has published a Handbook on Health Impact Assessment with the specific intent of assisting public health practitioners to participate in the EA process (Health Canada, 2004a, 2004b, 2004c, 2004d). This extensive handbook provides guidance on how to engage in the general EA process in addition to background information in a wide range of areas from communication to risk assessment.

In addition, the use of Health Impact Assessment (HIA) tools (Wismar et al., 2007; Lauzière, 2008; Bourcier et al., 2015; Metro Vancouver, 2015) can allow for a more systematic and consistent integration of health into EAs (Bhatia, 2007; Wernham, 2007; Bhatia and Wernham, 2008). HIA is a decision support tool used to predict future health impacts of a program, policy, or development that involves the use of logic and a variety of mixed methods including epidemiology, toxicology, and sociological reasoning (Wismar et al., 2007). HIA tools could be used to facilitate the linkage of the environmental, social, and economic impacts that are already assessed in an EA to the potential health impacts and collate them in one document for public health review and public comment.

\section{Conclusions}

Traditionally in environmental public health, the focus has been on local exposures to specific agents in the environment after these exposures have already occurred. However, the upstream environmental factors that can have both direct and indirect impacts on health in the future also require attention. Given the insufficient and inconsistent 
incorporation of health into current EAs there is an opportunity for public health practitioners to advocatefor and facilitate the effective integration of health into EAs in the future.

Slides from a panel discussion on Putting Health in Environmental Assessments (http://www.ncceh.ca/content/puttinghealth-environmental-assessment) and a workshop on Health Impact Assessment in Environmental Health (http://www. ncceh.ca/content/health-impact-assessment-environmental-healthmethods-tools-and-policy-change) can be found on our website. These slides provide some examples of public health's role in environmental assessment. Resources regarding health impact assessment are also available on the NCCHPP website (www.ncchpp.ca).

We would like to hear from you. Have you been involved in environmental assessments? To what capacity have you been involved? Do you have experiences that are different from those presented here? Please contact us at contact@ncceh.ca

\section{Acknowledgements}

We would like to thank Helen Ward and Lydia Ma for their input. Production of this article has been made possible through a financial contribution from the Public Health Agency of Canada.

\section{References}

Bhatia, R. 2007. Protecting health using an environmental impact assessment: A case study of San Francisco land use decision making. Am. J. Public Health. 97(3): 406-413. doi: 10.2105/ AJPH.2005.073817.

Bhatia, R. and Wernham, A. 2008. Integrating human health into environmental impact assessment: An unrealized opportunity for environmental health and justice. Environ. Health Perspect. 116(8): 991-1000. doi: 10.1289/ehp.11132.

Bond, A. 2004. Lessons from EIA. In J. Kemm, J. Parry, and S. Palimer (Eds.), Health impact assessment: Concepts theory, techniques and applications. Oxford, UK: Oxford University Press.

Bourcier, E., Charbonneau, D., Cahill, C. and Dannenberg, A.L. 2015. An evaluation of health impact assessments in the United States, 2011-2014. Prev. Chronic Dis. 12: E23. doi: 10.5888/pcd12. 140376.

Davies, K. and Sadler, B. 1997. Environmental assessment and human health: Perspectives, approaches and future directions. Ottawa, ON: Health Canada. Available at http://siteresources.worldbank. org/INTRANETENVIRONMENT/1705736-1127758054592/ 20677752/Sadler-HealthAspectsOfEnvAssessment.pdf.

Health Canada. 2004a. Canadian handbook on health impact assessment. Volume 1: The basics. Ottawa, ON: Health Canada. Available at http://www.hc-sc.gc.ca/fniah-spnia/pubs/promotion/_ environ/handbook-guide2004/index-eng.php.

Health Canada. 2004b. Canadian handbook on health impact assessment. Volume 2: Approaches and decision-making. Ottawa,
ON: Health Canada. Available at http://www.hc-sc.gc.ca/fniah-spnia/ pubs/promotion/_environ/handbook-guide2004/index-eng.php.

Health Canada. 2004c. Canadian handbook on health impact assessment. Volume 3: The multidisciplinary team. Ottawa, ON: Health Canada. Available at http://www.hc-sc.gc.ca/fniah-spnia/ pubs/promotion/_environ/handbook-guide2004/index-eng.php.

Health Canada. 2004d. Canadian handbook on health impact assessment. Volume 4: Health impacts by industry sector. Ottawa, ON: Health Canada. Available at http://www.hc-sc.gc.ca/fniah-spnia/pubs/ promotion/_environ/handbook-guide2004/index-eng.php.

Kwiatkowski, R.E. 2004. Impact assessment in Canada: An evolutionary process. In J. Kemm, J. Parry, and S. Palimer, (Eds.), Health impact assessment: Concepts, theory, techniques and applications. Oxford: Oxford University Press; 2004.

Kwiatkowski, R.E. and Ooi, M. 2003. Integrated environmental impact assessment: A Canadian example. Bull. World Health Organ. 81(6): 434-438. Available at http://www.who.int/bulletin/ volumes/81/6/kwiatkowski.pdf.

Lauzière, J. 2008. Health impact assessment: Guides and tools inventory. Montreal, QC: National Collaborating Centre for Healthy Public Policy. Available at http://www.ncchpp.ca/docs/ HIAGuidesTools2008en.pdf.

McCaig, K. 2006. An evaluation of health impact assessment in Canada using four case studies from the mining industry. MSc thesis, University of British Columbia, Vancouver, BC, 2006. Available at https://circle.ubc.ca/handle/2429/17774.

Metro Vancouver. 2015. Health impact assessment of transportation and land use planning activities. Burnaby, BC: Metro Vancouver. Available at http://www.metrovancouver.org/services/regionalplanning/PlanningPublications/HIA-Guidebook.pdf.

Noble, B. and Bronson, J. 2006. Practitioner survey of the state of health integration in environmental assessment: The case of northern Canada. Environ. Impact Assess. Rev. 26(4): 410-424. doi:10.1016/j.eiar.2005.11.001

Noble, B.F. and Bronson, J.E. 2005. Integrating human health into environmental impact assessment: case studies of Canada's northern mining resource sector. Arctic. 58(4): 395-405. Available at http://pubs.aina.ucalgary.ca/arctic/arctic58-4-395.pdf.

Orenstein, M., Fossgard-Moser, T., Hindmarch, T., Dowse, S., Kuschminder, J., McCloskey, P., et al. 2010. Case study of an integrated assessment: Shell's North Field Test in Alberta, Canada. Impact Assess. Project Appraisal. 28(2): 147-157. doi: 10.3152/ $146155110 \mathrm{X} 498816$.

Wernham, A. 2007. Inupiat health and proposed Alaskan oil development: Results of the first integrated health impact assessment/ environmental impact statement for proposed oil development on Alaska's North Slope. EcoHealth. 4(4): 500-513. doi: 10.1007/ s10393-007-0143-z.

Wismar, M., Blau, J., Ernst, K. and Figueras, J. 2007. The effectiveness of health impact assessment. Scope and limitations of supporting decision-making in Europe. Copenhagen, Denmark: European Observatory on Health Systems and Policies, WHO Regional Office for Europe.

World Health Organization. 2015. The determinants of health. Geneva: WHO. Available from: http://www.who.int/hia/evidence/ doh/en/ [accessed 28 July 2015]. 